ARTIGOS

\title{
Cerimônia na alfabetização de jovens e adultos: aparato performático
}

\section{Ceremony in youth and adult literacy: performative apparatus}

\author{
Rosângela Tenório de Carvalho (i)
}

(i) Universidade Federal de Pernambuco - UFPE, Recife, PE, Brasil. https:/ /orcid.org/0000-00031025-4736, rosangelatc@gmail.com

Resumo: A ação alfabetizadora pode ser analisada como um ritual de passagem da cultura oral para cultura escrita, na qual se atribui uma nova identidade - a do sujeito alfabetizado - e uma nova relação social a partir do enunciado sei ler. Neste artigo, a partir de uma análise de registro de cerimônias de abertura e de encerramento de Cursos de Alfabetização de Jovens e Adultos, sob a noção de cerimônia no campo da antropologia social de Stanley Tambiah, em convergência com o modo de problematizar os rituais de Michel Foucault, foi possível identificar como tais cerimônias, pelo seu efeito performático, constituem um aparato importante na produção do sujeito educado.

Palavras-chave: alfabetização de adultos, cerimônias, performatividade

Abstract: The literacy action can be analyzed as a ritual of passage from oral culture to written culture, in which a new identity is attributed, the literate subject, as is a new social relationship, from the statement "I can read". In this article, from an analysis of the registers of opening and closing ceremonies of Youth and Adult Literacy courses, under the notion of ceremony from the field of social anthropology by Stanley Tambiah, in convergence with the way of problematizing rituals by Michel Foucault, it was possible to identify how, because of their performative effect, such ceremonies are an important apparatus in the production of the educated subject.

Keywords: adult literacy, ceremonies, performativity 


\section{pro.posıções}

$e$-ISSN 1980-6248

http://dx.doi.org/10.1590/1980-6248-2016-0080

\section{Introdução}

Sontag (2015a), em Entrevista completa à Revista Rolling Stone, ao tratar da necessidade que tem de pensar sobre o que está experimentando, de prestar atenção ao mundo que a inclui, diz "se a gente não pensa nas coisas, acaba sendo veículo dos clichês do momento, mesmo dos mais inteligentes" (p. 21). Brayner (2014), em seu instigante artigo "O clichê: notas para uma derrota do pensamento. Por uma consciência ingênua", sugere o uso do clichê como uma forma de subtrair as pessoas do exame crítico. Ainda que o clichê não seja o nosso objeto de análise neste artigo, sob a inspiração desses textos, disponibilizamo-nos a pensar sobre enunciados cristalizados do pensamento ou da expressão em práticas ritualísticas profanas no campo da Educação de Jovens e Adultos.

Desde meados dos anos 1980, temos observado, em cerimônias de abertura ou de encerramento de programas de alfabetização de jovens e adultos, expressões cristalizadas nas narrativas de alfabetizandos: o agradecimento às autoridades presentes pela possibilidade de ter aprendido a ler; a honra de partilhar da presença dessas autoridades; a vergonha que sentiam por não saberem ler; e, finalmente, o reconhecimento de que antes eram cegos, não sabiam de nada, mas que, a partir daquele momento, podiam ver. Esses enunciados, transmitidos por palavras, gestos, constituem, parece-nos, uma ação de deferência no sentido dado por Goffman (2011), ou seja, uma forma de comunicação simbólica de demonstração do alfabetizando sobre aquelas autoridades e, ao mesmo tempo, um modo de reputar essa ação como honra. Lembranos Barthes (1988), ao dizer que a honra é "geralmente uma sobra do poder" (p. 69). Esses enunciados, quando no contexto de práticas ritualísticas, como cerimônias, podem ensejar interrogarmo-nos sobre a objetivação de modos de ser e estar na sociedade na condição de sujeitos alfabetizandos.

As cerimônias de abertura ou encerramento de programas de alfabetização de adultos ganharam relevância nos últimos 50 anos, de modo que participam delas lideranças políticas; representantes da burocracia educacional, de órgãos internacionais e de movimentos sociais; educadores(as); empresariado; e celebridades, além dos alfabetizandos e dos alfabetizados, com os seus familiares e amigos. Essas cerimônias constituem rituais profanos da escolarização com a função de ponto de ancoragem do governo sobre os sujeitos escolarizados ou em processo de escolarização, pois podem assegurar um estatuto no qual a alfabetização é investida como ação 


\section{pro.posições}

$e$-ISSN 1980-6248

http://dx.doi.org/10.1590/1980-6248-2016-0080

de cidadania, mudança, emancipação, possibilidade de evolução dos indivíduos e desenvolvimento social nas sociedades contemporâneas.

Tal função pode ser entendida quando analisada como uma ação performática no sentido dado por Tambiah (1995), com seus enunciados conotativos em sua força de citacionalidade no contexto de uma cosmologia. Essa ação confere, em âmbito singular da alfabetização de adultos, os valores da educação como processo de humanização e de cidadania, tal como estão proclamados nas sociedades modernas.

O objeto central desse tipo de cerimônia é a ação alfabetizadora, e é ela que é engrandecida em consequência de sua função enunciativa no projeto de produção da cultura nacional e do cidadão humanizado no mundo moderno. Historicamente o discurso da cultura nacional "contribuiu, para criar padrões de alfabetização universais, generalizou uma única língua vernacular como meio dominante de comunicação de toda nação" (Hall, 1999, p. 50). Contudo, tal padrão foi seletivo, classificatório, como sugere Sloterdijk (2000, p. 44), ao argumentar que a alfabetização no contexto do que se reconhece como formação humana tem seus efeitos seletivos, dentre eles, o modo como fraturou as sociedades, ao cavar um fosso intransponível entre pessoas letradas e iletradas. Parece-nos estar em consonância com o argumento da ação alfabetizadora como uma ação biopolítica e de governamentalidade, no sentido dado por Cavalcante (2016), ao analisar procedimentos do poder no processo de criação da população não alfabetizada como alvo das tecnologias do constrangimento e do abandono, no próprio seio do discurso alfabetizador.

Problematiza Sloterdijk (2000) a visão do humanista sobre a formação de seres humanos: "o humanista assume o homem como dado de antemão e aplica-lhe então seus métodos de domesticação, treinamento e formação - convencido que está das conexões necessárias entre ler, estar sentado e acalmar" (p. 40). Tal processo aparece em outras narrativas, como no texto literário de Máximo Gorki (1976) em Pequenos burgueses: "Piotr: Eu pensava: termino os meus estudos, vou ser advogado, vou trabalhar... Vou ler, observar... Vou viver!" (p. 50).

A ação alfabetizadora no contexto de cerimônias de abertura e de encerramento de Cursos de Alfabetização de Jovens e Adultos traduz-se no ritual de passagem do oral para o escrito. Mesmo que se entenda que não existe mais uma cultura tradicionalmente oral, tal como 


\section{pro.posições}

$e$-ISSN 1980-6248

http://dx.doi.org/10.1590/1980-6248-2016-0080

foi tratada no domínio religioso e dos clérigos, quando do acesso à leitura da Sagrada Escritura, tendo em vista que vivemos em um mundo da cultura, no qual praticamente todos os espaços culturais são de convivência com artefatos culturais, como defende Rivière (1996).

O objetivo deste artigo é sugerir que, em sua dimensão ritualística, essas cerimônias estariam relacionadas com um contexto maior de normas, de convenções e práticas culturais e tradições de eventos públicos em sua ação performática. Nesse sentido, interessa verificar os modos como as coisas são ditas pelos adultos alfabetizandos ou alfabetizados na circunstância da cerimônia. O estudo não remete a uma etnografia com uma descrição de atos presenciados, nem mesmo à dimensão do vivido no contexto da situação. O nosso objeto de análise advém de registros de cerimônias na história da alfabetização de adultos, como a sessão de encerramento do curso de alfabetização, realizada em Angicos no dia 2 de abril de 1963; a Cerimônia da VII Semana da Alfabetização - AlfaSol e Cerimônia do programa estadual da Bahia Todos Pela Alfabetização em 2010. Esses registros foram selecionados de um corpus maior, da pesquisa "A arqueogenealogia da lição: o ritual da lição como uma técnica de si na Educação de Jovens e Adultos". São registros em textos e imagens que estão em livros, revistas acadêmicas, livros didáticos, cadernos escolares, jornais, sites. Sob inspiração de Lévi-Strauss (1989), ao afirmar a história como um conjunto descontínuo, elegemos desse corpus registros não por uma ordem temporal de ocorrências, mas registros possíveis de serem trabalhados como discurso e pragmática. Registros de cerimônias com um tipo normativo de enunciação ou modalidade enunciativa; registros com um sistema de conceitos permanentes, numa inspiração foucaultiana de análise.

Essa perspectiva justifica o registro da cerimônia de 1963 como um acontecimento, por apresentar em seu conteúdo um corpo de concepções e normas com forte possibilidade de repetição no campo da alfabetização de adultos, e a análise de cerimônias dos anos 2010 no contexto da regularidade enunciativa, tal como Foucault designa para qualquer performance verbal uma ordem, posições, correlações em um campo singular de aparecimento. A regularidade não se apresenta de maneira definitiva, está sujeita a formas de articulação e coexistência discursiva em seu campo de presença, ou seja, enunciados já formulados e que são retomados a título de verdade admitida, em seu campo de concomitância, ao se referirem a domínios de objetos inteiramente diferentes, mas que atuam entre os enunciados estudados, e no domínio de memória, isto é, no que se refere aos enunciados em relação aos quais se estabelecem laços de 


\section{pro.posıções}

http://dx.doi.org/10.1590/1980-6248-2016-0080

$e$-ISSN 1980-6248

filiação, gênese e transformação, continuidade e descontinuidade histórica (Foucault, 1995). Vale dizer, contudo, que nos registros reescritos analiticamente interessou, prioritariamente, o aspecto performativo, ou seja, aquilo que marca posições, gestos e comportamentos, e, nesse sentido, o discurso dos alfabetizandos é o foco da análise.

\section{Cerimônias e performatividade}

Esta seção trata do mapa cognitivo de orientação para construção do argumento da análise apresentada. Apresentamos uma conceitualização no contexto dos discursos no campo das Ciências Humanas, aqui organizados os enunciados: origem profana da cerimônia; cerimônia forma cultural de significações; e cerimônia aparato performativo.

\section{Origem profana da cerimônia}

Embora a etimologia da palavra "cerimônia" remeta ao sânscrito, kar fazer, môn alguma coisa, ou seja, a coisa feita, a coisa sagrada, sua origem é profana, diz Rivière (1996). Foi aplicada a ritos cívicos solenes antes de se referir às formas exteriores regulares da celebração de um culto religioso. Tal como Rivière, Agamben (2009, p. 14) tem argumentado sobre essa origem profana, ao tratar a possibilidade de contraponto aos dispositivos que nos capturam em sua ação subjetivadora. Observa Agamben (2009) como, por meio de rituais minuciosos, "o sacrifício sanciona em cada caso a passagem de alguma coisa profana para o sagrado, da esfera humana para aquela divina" (p.14). Pondera, porém, que o que "foi ritualmente separado pode ser restituído pelo rito à esfera profana" (p. 14). Incute pensar que "a profanação pode atuar como um contradispositivo que restitui ao uso comum aquilo que o sacrifício havia separado e dividido" (p.14).

A cerimônia saudada como prática importante no contexto dos ritos, a exemplo de escolas filosóficas da Grécia antiga, tal como a crença orfismo, fundada por Orfeu, em sua potência para o alcance de uma vida mais elevada ou na religião cristã, igualmente a outras práticas ritualísticas, abrange atos estereotipados, simbólicos e repetitivos do campo secular e do campo eclesial. No discurso religioso, diz-se que a cerimônia tem aspecto de execução solene 


\section{pro.posições}

$e$-ISSN 1980-6248

http://dx.doi.org/10.1590/1980-6248-2016-0080

de um ato, a exemplo do culto divino, com um roteiro prévio que deve ser observado, ou seja, uma liturgia tal como está no dicionário ilustrado das religiões.

Fora do contexto religioso stricto sensu, a cerimônia no contexto da escolarização pode ser vista como um rito de passagem. Turner (2013) realça o rito de passagem como um dos ritos de crises da vida e, nesse sentido, fala em "sujeitos rituais marcados por um certo número de momentos críticos de transição, que todas as sociedades ritualizam e assinalam publicamente com práticas adequadas para gravar a significação do indivíduo” (pp. 156-157). Ressalta ainda que esse tipo de ritual está associado aos ritos de elevação de status de inversão de posição social. Suas análises sobre o ritual de passagem, a exemplo dos seus estudos com o povo ndembu, contribuem para uma rica formulação sobre drama social, símbolo ritual e performance. Identifica como unidade de análise fundamental o drama social como ação substantiva de onde deriva a diversidade da performance cultural. Sua compreensão do ritual como uma ação performativa é produzida em uma feliz confluência entre enunciados do campo artístico - o teatro em particular -, o campo da linguagem, a literatura oral, a etnomusicologia, os estudos do folclore e a antropologia cultural contemporânea.

Diferente de Turner, Bourdieu (2004, p. 196) prefere falar em ritos de passagem como atos de instituição. Em sua proposição, nesse tipo de rito, há uma morte para se dar vida à instituição, ou seja, com o rito institui-se uma nova ordem que remete à ordem estabelecida. Ao falar do ritual no contexto institucional, em seu brilhante texto Lições de aula, Bourdieu (1994) indica qual a função dos ritos na instituição dos sujeitos sociais. Para ele, os ritos de instituição forjam uma imagem social do sujeito social, ou seja, o instituem, o constituem, o intimam "a tornar-se o que é, ou seja, o que ele tem de ser obrigam-no a cumprir sua função, a entrar no jogo, na ficção" (p. 55).

Diz Rivière (1996) que o rito institui no sentido em que sanciona uma ordem estabelecida, e que o ato solene de investidura próprio de um rito de passagem produz o que designa como "magia performática" (p.44). Essa formulação interessa-nos pela força que dá ao caminho investigativo pelo qual optamos, que considera o ritual como um ato de enunciação, onde o dito é feito, ao modo de dizer de Peirano (2003). 


\section{pro.posições \\ $e$-ISSN 1980-6248}

http://dx.doi.org/10.1590/1980-6248-2016-0080

\section{Cerimônia forma cultural de significações}

Em seu texto Rituais, ontem e hoje, Peirano (2003), ao descrever a historiografia canônica do ritual, indica, como um dos pensamentos dominantes no início do século XX, a possibilidade para ajudar a esclarecer formas elementares de sociabilidade, tal como foi defendida por estudiosos, a exemplo de Émile Durkheim. A autora traz também o papel de Lévi-Strauss para os estudos antropológicos e sua significação para a antropologia.

Com efeito, Durkheim (1984), em seus estudos sobre as religiões, observa como os ritos "traduzem alguma necessidade humana, algum aspecto da vida, seja individual ou social" (p. 148). Ao considerar que as grandes instituições sociais nasceram da religião, afirma que "as regras da moral e do direito foram indistintas das prescrições rituais” (p. 169), daí a importância dos rituais nas práticas sociais. Dentre esses rituais, os coletivos, as cerimônias que são elas mesmas, expressam sacralidades confirmadas por atos simbólicos.

O trabalho de Durkheim foi considerado importante por autores diversos, a exemplo de Woodward (2000) e Ortiz (2012), sobretudo por sua ênfase em sistemas classificatórios, no sagrado e no privilégio do simbólico. Tais autores seguem uma linha de reflexão na qual buscam observar possibilidades de uso de uma conceitualização trazida por Durkheim para compreensão de práticas sociais específicas da atualidade. Woodward (2000) ressalta em Durkheim que “não existe nada inerentemente ou essencialmente 'sagrado' [ênfase no original] nas coisas. Os artefatos e ideias são sagrados apenas porque são simbolizados e representados como tais" (p.40). Lembra como ele argumentava sobre a necessidade de exame dos significados partilhados que caracterizam os diferentes aspectos da vida social no aspecto fundamental como eles são classificados simbolicamente. Afinal, é por meio de rituais que o sentido é produzido, momentos nos quais ideias e valores são apropriados pelos indivíduos, inclusive em rituais simples da vida diária, como as refeições, dizia Durkheim.

Ortiz (2012) trata de mostrar como a dimensão simbólica no estudo de Durkheim desafia a imaginação sociológica do leitor contemporâneo. E essa dimensão simbólica é apreendida por meio da noção do sagrado como algo "que se acrescenta, se sobrepõe ao real; trata-se de uma realidade de segunda ordem" (p. 20). No que se refere ao sagrado e ao profano, observa como Durkheim faz a distinção entre os dois como mundos incongruentes, mas que precisam se comunicar entre si. Aproximar esses polos antagônicos seria a função de ritos 


\section{pro.posıções}

$e$-ISSN 1980-6248

http://dx.doi.org/10.1590/1980-6248-2016-0080

empreendidos por especialistas. Por fim, o autor traz também a capacidade de simbolização naquele sociólogo como uma condição da vida social, já que “a vida social inexiste sem o mecanismo da representação simbólica, essa 'realidade de segunda ordem' [ênfase no original] é constitutiva do que denominamos sociedade” (p. 22). Pressupõe também Ortiz que o raciocínio apresentado por Durkheim "é semelhante ao dos linguistas quando abordam a língua como uma faculdade do ser humano" (p. 22). Quanto ao problema das classificações do pensamento, observa que o sociólogo desenvolve uma reflexão sobre as categorias do pensamento que não seriam inatas, universais, e sim sociais, e que cada sociedade teria formas singulares de apreensão do mundo.

Contudo, há um aspecto que Ortiz (2012) ressalta e que aproxima o Durkheim da antropologia ao modo de pensar desenvolvido por Lévi-Strauss, quando defende que as categorias de classificação antecedem os conteúdos do pensamento; elas constituem as formas por meio das quais eles são ordenados e hierarquizados (p. 25).

No campo estrito da Antropologia, Lévi-Strauss (1989), para defender o ritual como uma linguagem, faz uma diferenciação entre ritual e mito. Para ele, o ritual é a forma como as coisas são ditas, e o mito refere-se ao que dizem as palavras. O ritual é conjuntivo, implica uma relação entre grupos que, no processo, se confundem (p. 49). Em seu clássico texto O pensamento selvagem, Lévi-Strauss (1989) apresenta um conjunto de aspectos relevantes para o estudo do ritual, a exemplo da instabilidade lógica de uma ação ritualizada, a simbolização da atividade (p. 163); a linguagem lexical, a capacidade de ressignificação de palavras de uso corrente para a língua sagrada, reservada ao ritual, "onde perdem progressivamente a significação, sendo a língua sagrada, por definição, ininteligível aos não iniciados e parcialmente liberta de função significante para os próprios não iniciados" (p. 232); e, também o trabalho da classificação no contexto do ritual, ao defender que "toda classificação é superior ao caos, e mesmo uma classificação no nível das propriedades sensíveis é uma etapa em direção a uma ordem racional ... mesmo no plano da percepção estética, a classificação tem seu mérito” (pp. 30-31).

Sontag (1987) chama a atenção para o modo como Lévi-Strauss opera com o conceito de ritual e ressalta que, em Lévi-Strauss, todo o comportamento é uma linguagem, um vocabulário e uma gramática da ordem. Essa observação é importante, ao nos indicar a importância do contexto no ritual, pois, tal como os sons das palavras que não possuem um significado próprio, os elementos de um rito não têm um sentido próprio, assim como no caso 


\section{pro.posıções}

$e$-ISSN 1980-6248

http://dx.doi.org/10.1590/1980-6248-2016-0080

do mito. O sentido é produzido no contexto, ou melhor, "só ao serem montados no contexto global, os elementos possuem um significado" (p. 99).

Por outro lado, não se pode deixar de lado a crítica ao estruturalismo de Lévi-Strauss. Essa crítica incide principalmente no aspecto binário da linguagem e no caráter não social do simbólico, aspectos que estariam na base do pensamento de Saussure, em suas análises estruturalistas ligadas à lógica subjacente de toda linguagem e de todo pensamento.

Butler (2003) faz uma instigante proposição, ao tratar de outras formas de parentesco; vejamos o que ela diz em relação ao sentido dado por Lévi-Strauss: “o parentesco é uma maneira de gerar uma estrutura social e política por meio da manipulação do casamento e descendência" (p. 190). Não obstante, alerta que "especialmente em sociedades complexas como esta, o parentesco pode significar simplesmente as relações sociais de ajuda, intimidade e ligação duradoura. Essa forma de usar o termo parentesco é muito diferente da concepção de parentesco de Lévi-Strauss” (p. 190).

Para a autora, a concepção de parentesco de Lévi-Strauss é importante, quando se analisam sociedades governadas por relações de parentesco obrigatórias. Contudo insuficiente para analisar a vida social nas sociedades contemporâneas, nas quais o parentesco perdeu um pouco o status obrigatório.

No campo estrito da Antropologia, há uma crítica com as oposições binárias cristalinas, como natureza/cultura, corpo/mente, paixão/razão. Argumenta-se que, quando se colocam esses termos em oposição, sempre um é mais valorizado do que outro; há um desequilíbrio necessário de poder entre eles. Woodward (2000), recorrendo ao que está sugerido por Derrida, observa como no campo dos estudos feministas se faz uma forte crítica: o significado e o significante não são algo fixo. O significado é produzido por meio de um processo de diferimento ou adiamento - différance. Nesse sentido, há um deslocamento do conceito de fixidez para o conceito de contingência, ou seja, o significado em relação ao significado. Essa referência, como outras, faz com que estudos no campo da antropologia andem juntos com estudos pósestruturalistas, discursivos e outros.

Malgrado as críticas, vale ressaltar que grande parte dos estudos sobre subjetividade e performatividade no campo da antropologia se baseou nos importantes estudos de Lévi-Strauss 


\section{pro.posições}

$e$-ISSN 1980-6248

http://dx.doi.org/10.1590/1980-6248-2016-0080

sobre as relações de parentesco, com todo o seu arcabouço - as manifestações simbólicas e, principalmente, a internalização dessa estrutura universal de parentesco nas pessoas.

No artigo em tela, uma analítica que privilegie a reflexão sobre performatividade está próxima do pensamento de sujeito produzido na contingência da história e da cultura (Foucault, 1995) e no sentido da flexibilidade do ritual, considerando-se os contextos em que são realizados (Tambiah, 1995).

\section{Cerimônia, um aparato performativo}

Segundo Abbagnano (2007), "performativo" foi o nome dado por L. Austin a enunciados que têm dois aspectos: a) não descrevem, não relatam e não constatam nada, não são verdadeiros ou falsos; b) ao serem pronunciados, realizam uma ação ou criam uma parte dela. Um exemplo: "Eu prometo". Expressão que exprime um compromisso, uma ação, com uma força intrínseca que o autor chama de "ilocucionária". Essa perspectiva de Austin foi incorporada à antropologia de Tambiah (Peirano, 2002, p. 10).

Com efeito, no campo dos estudos antropológicos que tratam as práticas ritualísticas como performáticas, ganha relevo o papel da linguagem em sua produtividade da ação humana. Sontag (2015b), ao argumentar sobre a estética do silêncio, recorre à filosofia da linguagem de Wittgenstein, no sentido de que a linguagem "é regularmente empregada para inspirar a ação, certas declarações verbais, sejam escritas ou orais, são elas próprias o desempenho de uma ação (como ao se prometer, jurar, legar)" (p. 27) e também lembra com o filósofo que "o significado é o uso" (p. 37). De certo modo, a ensaísta está chamando a atenção para o poder da linguagem.

A relação intrínseca entre antropologia e uma teoria da linguagem é asseverada por Peirano (2002): "linguagem e cultura não se relacionam como reflexos em um espelho, como os dois lados de uma folha de papel, mas como parte e todo: a linguagem é parte da cultura" (p. 11). Para a antropóloga:

Se, no entanto, aceitamos que a linguagem extrapola a função referencial, abrimos espaço para usos e funções (culturais) da linguagem que derivam do que Malinowski (1930) chamou de "contexto da situação" [ênfase no original]. Tais funções e usos decorrem de propriedades intrínsecas à linguagem, isto é, não são acrescidas depois ou quando a língua é posta em uso; elas são inerentes ao fenômeno mesmo da linguagem (aqui, os nomes de referência são, 


\section{pro.posıções}

$e$-ISSN 1980-6248

http://dx.doi.org/10.1590/1980-6248-2016-0080

naturalmente, Peirce, Jakobson e Austin). O caso dos pronomes pessoais é exemplar de um signo no qual o aspecto referencial e o indéxico se combinam: dependendo de quem enuncia e para quem se enuncia, o significado dos pronomes muda. (p. 28)

Peirano (2002) reforça que determinados verbos são, por sua própria natureza, performativos, e é nesse sentido que defende que dizer é fazer. Peirano está associada ao modo como Austin (1990) argumentou que há proferimento da sentença, que "é, no todo ou em parte, a realização de uma ação, que não seria normalmente descrita consistindo em dizer algo" (p. 24). Ou seja, Austin chama a atenção para enunciados performativos, aqueles que têm a função de ação performativa como atos de fala expressos em pedidos, ordens, promessas. Nessa perspectiva, a linguagem não apenas nomeia, representa, ela se transforma em ação, ela performatiza. Para Austin (1990), os enunciados constatativos também podem, sob certas circunstâncias, atuar como performativos: uma declaração de fato pode acabar produzindo o "fato" que supostamente apenas descreve (p. 12).

É com Peirano que nos aproximamos da relação entre ritual e performatividade. Por meio dos seus estudos, chegamos a Stanley Tambiah (1995), em particular, ao seu clássico texto Rituali e cultura. Com ele, vamos tratar o ritual considerando a sua proposição de unir semântica e pragmática. Isto é possível porque Tambiah funde o modelo linguístico estrutural de Saussure e Lévi-Strauss com o conceito de discurso desenvolvido por Austin, discurso como ato performático, e o conceito de signo na perspectiva semiótica de Pierce (Leonine, 1995).

Nesse aspecto, interessa a relação entre ritual e linguagem, isto é, o funcionamento da linguagem em termos performativos. Nessa perspectiva, em diálogo com Tambiah (1995), o ritual é visto como um sistema construído culturalmente e como um sistema comunicativo em contextos específicos.

O registro de Tambiah (1995) sobre essa questão o leva a apresentar uma abordagem do ritual do ponto de vista performativo. Por ritual entende, então:

Il rituale è un sistema di comunicazione simbolica constrito culturalmente. Constituito da sequenze di parole e atti, strutturati e ordinati e spesso espressi com molteplice mezzi, il cui contenuto e la cui disposizione sono caratterizzati in vario grado da formalismo (convenzionalita), stereotipia (rigidità) condensazione (fusione) $e$ ridondanza (ripetizione). Nelle sue caratteristiche constituive, l'azione rituale è performativo, in quiesti tre sensi: nel senso austiniano de performativo, incui dire qualcosa è anche fare qualcosa, in quanto atto convenzionale; nel senso, abbastanza diverso, di comunicazione, grazie al quali e partecipanti sperimentano intensamente l'evento; 


\section{pro.posições}

$e$-ISSN 1980-6248

e nel senso del valori inicati - ricavo questo concetto de Peirce - essendo connesso com (e inferito da) gli attori durante la rappresentazione. ( pp. 130-131)1

Para Tambiah, no ritual, o conteúdo cultural é radicado em uma cosmologia, ou seja, o corpo de concepções que elencam e classificam os fenômenos que compõem o universo como um todo ordenado, assim como as normas e os processos que os governam.

Para Foucault (1999), é por meio de rituais que se dão os jogos de verdade (conjunto de regras de produção da verdade), o olhar normalizador e a vigilância. Quanto ao ritual, observase o que defende o supracitado autor:

[O ritual] define a qualificação que deve possuir os indivíduos que falam (e que, no jogo do diálogo, na interrogação, na recitação, devem ocupar determinada posição e formular determinado tipo de enunciados); define os gestos, os comportamentos, as circunstâncias e todo o conjunto de sinais que devem acompanhar o discurso; o ritual fixa, por fim, a eficácia, suposta ou imposta, das palavras, o seu efeito sobre aqueles a quem elas se dirigem, os limites do seu valor constrangedor. Os discursos religiosos, jurídicos, terapêuticos, [pedagógicos] e em parte também os políticos, não são dissociáveis desse exercício de um ritual que determina para os sujeitos falantes, ao mesmo tempo, propriedades singulares e papéis convenientes. (p. 12)

Embora exista uma tensão na relação entre o modo de conhecer da antropologia e o modo de conhecer dos estudos culturais, dos estudos pós-modernos e dos estudos póscolonialistas, com os quais a análise em tela dialoga, pretendemos fazer uma ponte entre essas referências, para desenvolver a análise pretendida. Optamos por nos ligar ao modo como Tambiah (1997) vê essa tensão:

Minha visão particular é que os antropólogos devem ponderar essas considerações, digerir as críticas, e então prosseguir com seu trabalho de campo e escrita antropológicos, que devem incorporar criativamente as considerações pós-modernas. Por outro lado, devem admitir e assumir que diferentes formas de vida podem ser documentadas e que as circunstâncias e contextos de coleta de dados e representação autoral são parte do texto. Seria um erro dissolver a antropologia como disciplina ou reduzi-la a confrontos de egos altamente personalizados, que revelam mais as preocupações neuróticas de um outro invasor do que a riqueza das formas de

\footnotetext{
1 O ritual é um sistema de comunicação simbólica construído culturalmente. É constituído de sequências de palavras e atos, estruturado, ordenado e em geral expresso por múltiplos meios cujos conteúdo e arranjo são caracterizados por graus variados de formalidade (convencionalismo), estereotipia (rigidez), condensação (fusão) e redundância (repetição). Nos seus traços constitutivos, a ação ritual é performativa em três sentidos: no sentido austiniano de performativo no qual dizer alguma coisa é também fazer alguma coisa como um ato formal; no sentido bastante diverso, o das comunicações, graças aos quais os participantes experimentam intensamente o evento; e, no sentido dos valores indicados - tomo esse conceito de Peirce - conectados com valores inferidos pelos atores durante a performance. (Tradução nossa).
} 


\section{pro.posıções}

$e$-ISSN 1980-6248

http://dx.doi.org/10.1590/1980-6248-2016-0080

vida das outras sociedades, cujo conhecimento vai sempre aprofundar e iluminar nossas próprias vidas e sociedades. (p. 218)

Outros autores além de Tambiah desenvolveram esse conceito no contexto dos seus estudos filosóficos, tal como Jacques Derrida, diz Silva (2000), ao argumentar que o que caracteriza os atos de linguagem é sua "citacionalidade": a possibilidade de que eles sejam iterados, citados ou repetidos independentemente da presença de quem originalmente os emitiu ou recebeu. Buttler combina as contribuições desses dois autores para defender que a identidade de gênero e a identidade sexual são produzidas por meio de repetidos enunciados performativos. Jean-François Lyotard (1988), em $A$ condição pós-moderna, defende que, "em contraste com a era anterior, em que as narrativas científicas tinham sua legitimidade julgada de acordo com critérios de verdade, na era pós-moderna elas são julgadas de acordo com critérios de performatividade" (citado por Silva, 2000, pp. 90-91). Lyotard (1988), ao operar com essa conceitualização desenvoldida por Austin, ressalta como as mensagens são dotadas de formas e efeitos diferentes, conforme seu tom denotativo, prescritivo, avaliativo, performativo. Estranho saber, dir-se-á, que nem ao menos se faz compreender pelos jovens a quem se dirige (p. 40)!

De certa maneira, com essas referências, encontramos um caminho analítico que considera a singularidade de cada ação ritualística, sua dimensão formal e sua dimensão contextual. Nessas dimensões, é possível identificar a estrutura, a ordem, a cosmologia e, nas narrativas das experiências da alfabetização dos alfabetizandos ditas por eles mesmos, os enunciados conotativos. Interessam as experiências nas quais os sujeitos necessitam falar de si dentro de uma ordem do discurso (Foucault, 1999), de uma cosmologia (Tambiah, 1995). Na dimensão formal, observamos como começa e como termina a cerimônia, a ordem que a estrutura, o propósito, mas também o imponderável.

\section{Sessão de encerramento do curso de alfabetização, Angicos, no dia 2 de abril de 1963}

Tal como já indicado neste artigo, a cerimônia ritualística de encerramento do curso de alfabetização em Angicos no ano de 1963 é tratada como um acontecimento discursivo, no sentido de irrupção histórica que emerge como algo importante, de acordo com as regras que 


\section{pro.posições}

$e$-ISSN 1980-6248

http://dx.doi.org/10.1590/1980-6248-2016-0080

compõem as condições para esse acontecimento (Foucault, 1995); como ação performativa resultante da eficiência do ritual visto como um complexo de palavra e ação, conduzida em um contexto especial (Tambiah, 1995).

O contexto dessa cerimônia foi produzido no final dos anos 1950 e início dos anos 1960, no Brasil do pós-guerra em 1945 até ao golpe militar em 1964, quando “constituiu-se num cenário propício à elaboração de diferentes propostas e ações, nas áreas econômica, política e sociocultural, com o objetivo de superar o atraso e o subdesenvolvimento da nação" (Weber, 1984, p. 233). No campo adstrito da Educação, a pedagogia freiriana disputa com outros discursos a perspectiva emancipatória de transformação radical da realidade social.

O lugar de enunciação da cerimônia em análise, a cidade de Angicos, no Rio Grande do Norte, ficou conhecido pela extraordinária experiência de Alfabetização de Adultos sob a orientação do professor Paulo Freire. O programa foi iniciado em janeiro de 1963, sendo que a cerimônia de formatura ocorreu em 2 de abril daquele mesmo ano, contando com a presença da mais alta autoridade do País, o Presidente da República, João Belchior Marques Goulart; do Ministro da Educação, Paulo de Tarso Santos; do Governador, Aluísio Alves; entre outras autoridades, assim como de jornalistas, do próprio Paulo Freire, de educandos, de familiares e de amigos.

O espaço da sala de cerimônia, onde as autoridades sentaram juntas para receber os alunos, transforma-se em território cultural, que reflete os espaços vistos historicamente como lugares sagrados (das autoridades máximas) e lugares profanos (dos alfabetizandos). O reconhecimento da autoridade e dos papéis é dado pelos lugares que os sujeitos ocupam. A estrutura e a ordem da cerimônia estão de acordo também com a disposição do reconhecimento do saber dos participantes. Entender essa assimetria dos lugares remete a afirmações de Rivière (1996) sobre a existência de "formas de sacralidade fora da religião, nas quais se inscrevem vários ritos cotidianos" (p. 36), e também ao fascínio exercido por determinados domínios, como o poder, a ciência. Trata-se do saber operando como poder (Foucault, 1999), agregado ao poder político daquelas autoridades que ali estão.

Há uma ordem de quem fala, há um movimento pactuado para que nessas falas o conteúdo não destoe: as concepções sobre educação, cidadania, responsabilidades educacionais, 


\section{pro.posıções}

$e$-ISSN 1980-6248

http://dx.doi.org/10.1590/1980-6248-2016-0080

projeto de país precisam estar aparentemente em consenso, controladas. É a "magia performática" (Rivière, 1996) que entra na ordem do rito de passagem.

Há uma cosmologia que une a todos os presentes, revelando um momento raro, pois somente nas práticas ritualísticas é que vamos encontrar, juntas, pessoas com modos de existência tão diversos (Tambiah, 1995). Por isso, na cerimônia, o ritual da fala em que a ordem do discurso orientado já é vista no primeiro discurso - do Governador do Estado e, na sequência, o discurso do Presidente da República, o do Educador Paulo Freire e o do alfabetizando. Nesses discursos, o Governador Aluísio Alves (2013) ressalta a experiência de alfabetização em massa, "cuja característica principal é a de ser feita no espaço de quarenta horas"(p. 163) e também o fato de que

mais de quatrocentos analfabetos, homens e mulheres de 20 a 70 anos, ...passaram a escrever e ler e a conhecer os problemas atuais, os problemas da nossa época, pelas aulas de politização que eram dadas simultaneamente com as aulas de alfabetização. (p. 164)

O discurso político do Presidente da República (Goulart, 2013) confirma, na sequência, a importância da alfabetização na formação do cidadão brasileiro e dá o tom na cerimônia da ação alfabetizadora como uma ação sagrada:

Aos alunos, às alunas, aos jovens, aos velhos e às senhoras, nesta $40^{\mathrm{a}}$ aula, as minhas homenagens e que Deus nos ajude e nos inspire, povo de Angicos e do Rio Grande do Norte, para podermos prosseguir nesta luta extraordinária, que constitui uma obrigação para todos nós, a luta a favor do alfabetismo, a luta a favor de melhores condições de vida para o nosso povo e de melhores condições de vida para a nossa Pátria. (p. 167)

Agradece de forma antecipada “as cartas mal traçadas, mas já escritas e escritas por gente que tem apenas 39 horas de preparo ... que aqueles que ainda há poucos dias eram analfabetos, se dirigem, agora, como alfabetizados, ao Presidente da República” (p. 167).

Segundo relatos históricos, o discurso do educando foi improvisado (Freire, 2006). Houve também a entrega de cartas dos alfabetizandos (as) ao Presidente da República. É o imponderável no ritual. Análises de rituais têm dado ênfase ao imponderável e à mudança no ritual, à linguagem em ação, à sociedade em ato (Peirano, 2006). Foi o que ocorreu naquele momento da cerimônia. A quebra do protocolo assegurou a essa cerimônia a consolidação do acontecimento discursivo. O que dizer diante de uma mesa com as mais altas autoridades do País? O que narrar e como narrar diante dos senhores em suas autoridades reconhecidas? Se o 


\section{pro.posıções}

$e$-ISSN 1980-6248

http://dx.doi.org/10.1590/1980-6248-2016-0080

ritual é uma festa, cabe, então, festejar. Se pessoas importantes estão presentes, prestigiando o seu aprendizado, então que se cuide das palavras, que se cuide dos pronomes de tratamento. Com o corpo, precisa-se também ter cuidado, pois há jornalistas gravando, fotografias estão assegurando o registro da ação. Nesse ritual, o modo de ser de cada um, os gestos, a postura e a expressão no discurso reafirmam a identidade dos presentes. Estamos em um rito de passagem como atos de instituição (Bourdieu, 2004), e nesse sentido o discurso de cada um assume uma função dada pela cosmologia. No caso do alfabetizando, o institui como alfabetizado, o constitui em sua função de leitor.

A dimensão formal prepara a cena para a fala, na qual o alfabetizando diz o que se espera que ele diga: ele deve falar dos conhecimentos que tinha antes e dos conhecimentos que tem agora; como era antes e como é agora, depois do programa; o que sabia e não tinha importância, e o que deve saber e como se comportar com esse saber. Ao tratar como majestade o Presidente, o alfabetizando coloca-se no lugar de quem reconhece a honra de estar presente ali na cena enunciativa. De certa maneira, há aqui uma similitude com o modo de tratar a honra por Barthes (1988) como a sobra do poder e a deferência por Goffman (2011). Ao expressar o seu agradecimento, ao mover o corpo, quase em uma genuflexão, o alfabetizando coloca-se no lugar de quem sente a honra de estar presente ali na cena enunciativa.

Senhor Presidente da República.

Senhor Governador Aluísio Alves e todos, autoridades que estão presentes.

Meus professores e minhas professoras e todos colegas. Em outra hora, há poucos dias, ninguém não sabia ler, não sabia de letras algumas, como eu era um que não sabia; só sabia o que era o $\mathrm{O}$, que era que nem a boca da panela, ou o A que era que nem um ganchinho de pau. E hoje em dia, graças a Deus e os meus professores, já assino o meu nome e leio argumas coisas, graças a Deus. Tanto que fiquei bastante sastisfeito com o alfabetismo que fez a nós aprendermos. Eu, já com a idade avançada, com 51 anos, mas graças a Deus tenho a inteligência e vou já escrevendo quarquer coisa. Hoje mesmo, já fiz uma cartinha para o Sr. Presidente da República, dizendo algumas coisas; e do mais que peço a sua majestade que é a pessoa maior que nós enxerguemos no Brasil, é o Presidente da República, quarqué coisa, ouviu, peço que continue o curso de aula para nós todos, não tão somente no Rio Grande do Norte como em todos os lugares por aí que têm necessidade, de milhares e milhares que não sabem as primeiras letras do alfabeto, são pessoas que têm necessidade, para melhorar a situação do Brasil, para mais tarde servir mesmo para o Senhor Presidente da República, para o Governador do Estado e para nós todos. Tanto que eu fiquei muito sastisfeito e mais sastisfeito ficarei continuando a escola. Naquele tempo anterior, veio o Presidente Getúlio Vargas matar a fome do pessoal, a fome da barriga - que é uma doença fácil de curar. Agora, na época atual, veio o nosso Presidente João Goulart matar a precisão da cabeça que o pessoal todo tem necessidade de aprender. Temos muita necessidade das coisas que nós não sabia e que hoje estamos sabendo. Em outra hora, nós era massa, hoje já não somos massa, estamos sendo povo. 


\section{pro.posições}

$e$-ISSN 1980-6248

http://dx.doi.org/10.1590/1980-6248-2016-0080

Nós todos, alunos, uns 300 e tantos ou 400, já sabemos escrever quarquer coisa, e ler outras coisas. Com a continuação, amanhã ou depois, sabemos escrever as cartilhas do Presidente da República, sabemos fazer quarquer coisa em favor do Brasil, em favor do Estado. Tanto que estamos bastante sastisfeitos com estas aulas e devemos continuar. Aqui eu faço pausa. Está me faltando uma música, e desculpe e a todos agradecido, ouviu? (Ferreira, 2013, p. 168)

A dimensão formal já é por si mesma performativa (Tambiah, 1995); a sessão de encerramento é um discurso: terminou o processo de alfabetização, temos alfabetizados, o ritual da circunstância exige, orienta para o futuro, para prosseguir, já que todos os que pelo programa passam podem agora dizer-se "já sei ler", mesmo que seja "já assino o meu nome e leio argumas coisas, graças a Deus". Todos saem em paz, pois essa é a função desse ritual que é realizado em conjunto por pessoas presentes. Os alfabetizandos agora têm modos de ser e de pensar como escolarizados.

Vale, contudo, agora, fazermos uma reflexão sobre essa cerimônia, tendo como referente a nossa interpretação do discurso educacional de Paulo Freire. Inicialmente, Freire (1963-2014) iniciou seu discurso no contexto da circunstância do ritual, assumiu o papel a ele atribuído no ritual, o de validar a ação educativa que estava sendo naquele momento solene dada a conhecer:

Senhor Presidente, Senhores Governadores.

É com muita satisfação e também com humildade, sobretudo humildade, que dirigimos nossas palavras, tentando numa síntese fundamentar o Sistema de educação em que está contido o método eclético, com que estamos conseguindo quase resultados mágicos, mas que, na verdade, não são mágicos, porque fundamentados em princípios de ordem científica, filosófica.

...

Um povo que decide, um povo que se levantou, um povo que começa a tomar consciência de seu destino e começa a interferir no processo histórico brasileiro irreversivelmente. E a educação que se há de se dar a este país, há de ser uma educação da coragem, uma educação que ajude esse povo que emergiu, a inserir-se no seu processo, o que vale dizer, uma educação que conscientize o povo brasileiro, para que ele faça realmente com os homens públicos, as reformas inadiáveis de que este país precisa. (Freire, 1963-2014, p. 47)

Nessa cosmologia na qual estava inserido, Freire quis dar a conhecer aos presentes o modo de atuação pedagógica nos Círculos de Cultura, ou seja, naquele ritual quis dizer de outro, daquele que deu significação a esse ritual maior. Revelou que, para iniciar o trabalho, situações sociológicas típicas, da área que ia ser alfabetizada foram criadas; apresentou slides com o tema que estava sendo trabalhado e abriu o debate, que permitiu operar o o diálogo. Afirmou que, no trabalho que estava desenvolvendo: "o homem é chamado ao diálogo e à análise das situações 


\section{pro.posições \\ $e$-ISSN 1980-6248}

http://dx.doi.org/10.1590/1980-6248-2016-0080

postas diante dele, como situações desafiadoras" (Freire, 1963-2014, p. 49). O ritual do Círculo de Cultura tem, nessa experiência, o diálogo como foco, e, nesse sentido, podemos dizer que esse diálogo é um dos operadores de subjetivação para o devir da afirmação cultural. Rituais nos quais, em dado contexto de debate, educandos, provocados a partir de slide sobre o conceito de cultura, argumentam: "Faço sapatos e tenho o mesmo valor do doutor que faz. livros"; "Eu nunca vi matar porco de espingarda”. Expressam um modo diferente de posição de sujeito, diferente da postura na cerimônia. Um ponto de fuga na cosmologia do ato cerimonial. Destacou Freire a importância na educação da experiência que direcione o sujeito da educação para o "fazer crítico, portanto a poder decidir e a seguir poder optar" (Freire, 1963-2014, p. 48). Vale dizer que a sua interdição no período da ditadura civil militar não impediu que essa pedagogia tenha se consolidado como um discurso no campo da Educação Popular na América Latina e em países da África. Nas últimas décadas sua obra passou a constituir objeto de reflexão em diversos países de diferentes continentes.

Essa cerimônia como um acontecimento discursivo tem a função de prática discursiva fundadora, pois foi disseminada no País, e tais experiências têm sido implementadas e, 50 anos depois, mantêm-se programas de alfabetização com as festas de formatura.

Com efeito, nos anos que se seguiram, as cerimônias alastraram-se pelo País afora e nelas o momento do discurso do alfabetizando(a) é o mais esperado. Tal como a entrega das cartas, prática ritualística que também foi incorporada às cerimônias de formatura da alfabetização de adultos. Nessas cartas, os agradecimentos, os pedidos de continuidade da escolarização e até o texto sem o rigor da língua escrita compõem o rito que emociona pelo esforço da escrita, enfim, um rito que autoriza os alfabetizandos a dizer o que já sabem e onde poderão chegar com a escolarização. $\mathrm{Na}$ seção que segue, trataremos de algumas dessas cerimônias. 


\section{pro.posıções \\ $e$-ISSN 1980-6248 \\ Cerimônia da VII Semana da Alfabetização, realizada em São Paulo em 2010}

As cerimônias de Alfabetização de Adultos dos anos 2010 estão implicadas com a intensificação do processo de globalização econômica, política e cultural, cujo cenário vem sendo traduzido como "sociedade do conhecimento", "sociedade de consumo", "revolução tecnológica comunicacional e informática". Identificam-se relações neocoloniais entre países; exclusão dos não escolarizados dos postos de trabalho; intensificação dos processos de emigração e emergência dos imigrantes como um fenômeno demográfico; conflitos sociais por cidadanias multiculturais, sobretudo nas áreas urbanas dos países da América Latina e particularmente no Brasil. Por outro lado, observam-se nesse cenário: práticas políticas de superação das relações neocoloniais na América Latina; hegemonia de governos democráticos de esquerda; fortalecimento das estruturas do Estado com a articulação do Mercado Comum Americano do Sul (Mercosul); fortalecimento da economia de mercado e também das redes de economia solidária; discussão sobre desterritorialização, vida urbana e vida rural; investimentos em políticas públicas de escolarização das populações; políticas sociais voltadas para atender a diversidade geracional, assim como a diversidade de gênero, raça, etnia e sexualidade; redes de movimentos sociais multiculturais ou redes de organizações não governamentais.

Esse cenário produziu a emergência de uma gramática híbrida e recorrente - consumo, empreendedorismo, flexibilização, competência, direitos humanos, solidariedade, interculturalidade, políticas de inclusão, legislações afirmativas, afirmação identitária. Gramática que aparece nos discursos de política educacional (Carvalho, 2012).

A proposição do Alfabetização Solidária (AlfaSol) emergiu nesse contexto no ano de 1997. Organização da sociedade civil, sem fins lucrativos, apresenta como um elemento de sua missão a redução dos altos índices de analfabetismo. Com inserção nacional, tem em seu corpo representantes de empresas privadas, instituições governamentais e não governamentais, instituições de ensino superior, ensino básico, mídias. A Alfabetização Solidária atendeu em uma década "cerca de 5,3 milhões de alunos e [capacitou] cerca de 244 mil alfabetizadores, em 2088 municípios brasileiros" (AlfaSol, 2006, p. 3).

As cerimônias de comemoração da alfabetização ou mesmo de início de programas têm uma formalização que as caracteriza e que, ao longo do tempo e ao mesmo tempo, é impactada 


\section{pro.posıções \\ $e$-ISSN 1980-6248}

http://dx.doi.org/10.1590/1980-6248-2016-0080

pelo contexto de influência de diferentes práticas econômicas, sociais e culturais do período em curso. Assim, a cerimonia analisada a seguir tem a singularidade desse contexto, interpenetrando a experiência ritualística no campo educacional.

Vamos ao ritual da Cerimônia de Abertura da VII Semana da Alfabetização pelo Programa AlfaSol. O registro desta cerimônia está organizado em três seções: Bons motivos para comemorar, Mais emoção e Depoimentos. A estrutura, a ordem e os enunciados estão no desenho dessas seções:

Abrem-se as portas da Sala São Paulo. Convidados tomam seus lugares. Após o terceiro sinal sonoro, a Orquestra de Heliópolis, sob a regência do maestro Roberto Tibiriçá, abre a Cerimônia da VII Semana da Alfabetização com a ópera "A Flauta Mágica”, de Mozart. Ao término, Zeca Camargo entra no palco e vai até o púlpito sob o impacto de música e efeitos de luzes coloridas. (AlfaSol, 2006, p. 5)

O ritual ocupa um lugar, um território. No sentido foucaultiano, o lugar, quando tratado como território, traduz "antes de tudo, uma noção jurídico-política"(Castro, 2009, p. 414). No território são produzidos sentidos, principalmente numa época em que se vive do espaço, da simultaneidade, da justaposição, do próximo e do longínquo, do lado a lado, do disperso, da experiência que se assemelha a uma rede que vai ligando pontos e se intersecta com a sua própria meada, como diz Foucault (2001). A produção de sentidos na dinâmica do ritual é produzida pela cosmologia, ou seja, as concepções de sociedade, as regras, as convenções, as relações sociais e culturais, tal como aprendemos com Tambiah (1995). É essa cosmologia que opera no aspecto performativo do ritual. Nesse sentido, na ação ritualística, o lugar, sua estrutura e sua organização são fundamentais.

As cerimônias em âmbito da AlfaSol tornaram-se recorrentes, mas esta em análise é uma grande comemoração, uma especial cerimônia, como realça uma das organizadoras: “ $O$ encontro, que já se tornou tradicional, este ano teve sabor ainda mais especial, pois comemorou também 10 anos de atuação da AlfaSol, " (Alfasol, 2006, p. 8).

$\mathrm{Na}$ Cerimônia da AlfaSol, a participação da sociedade está marcada pelos seus diferentes representantes: junto com fundadores e membros da AlfaSol, intelectuais de universidades, representantes do Ministério da Educação, executivos de grandes empresas brasileiras e estrangeiras, gerentes de bancos, especialistas em educação da Unesco, atores de grandes mídias, 


\section{pro.posıções}

$e$-ISSN 1980-6248

http://dx.doi.org/10.1590/1980-6248-2016-0080

educadores de redes públicas de ensino, professores alfabetizadores e participantes dos programas de alfabetização.

Lembramos, com Foucault (1999), que há uma qualificação para os indivíduos que falam em um contexto ritualístico, como ocorre em uma cerimônia. São esses pronunciamentos esperados por todos que asseguram a cosmologia do evento. Há uma expectativa em relação aos elogios, às aprovações, ao modo de usar as palavras, e também ao cuidado para que todos sejam contemplados. Vejamos alguns desses depoimentos:

É um trabalho maravilhoso. Estou muito emocionada em ver o êxito da AlfaSol no Brasil, um país com alto índice de analfabetismo. Estou muito impressionada em ver como foi possível armar uma rede de responsabilidade social em torno do tema alfabetização, articulando as empresas privadas, as universidades e as pessoas em torno de uma causa tão importante, diz Luz Cristina Pinzón. (AlfaSol, 2006, p. 8)

Artistas dão voz e interpretação a textos e cumprem o seu papel no ritual, tal como o fez Denise Fraga Oliveira, ao ler a redação da alfabetizadora Lucivânia Lobo de Oliveira, de Caririaçu (CE): "Eu fiquei realmente muito feliz quando recebi o convite para participar deste evento. O trabalho realizado pela AlfaSol é um exemplo para todo País" (AlfaSol, 2006, p. 9). Do mesmo modo, Lima Duarte leu o texto de um alfabetizando, Reginaldo Ribeiro Mota.

A estrutura ritualística mantém-se com os discursos de autoridades, de convidados e de alfabetizados(as). As histórias desses sujeitos são sempre o ponto alto, pois são histórias que gostamos de ouvir, dos milagres da alfabetização, da possibilidade de agora enxergarem, já que antes eram cegos. Para não se perderem os resquícios da dimensão religiosa que está na rede das práticas ritualísticas da cerimônia, o agradecimento a Deus em primeiro lugar.

Tradicionalmente considerado ponto alto da festa, os relatos emocionantes contam histórias de brasileiros simples, em sua maioria, antes distantes do universo do letramento, e que, após iniciarem o processo de alfabetização, mudaram suas vidas, passando a exercer sua cidadania com maior plenitude. O tema do concurso este ano foi "Os melhores anos de minha vida". (AlfaSol, 2006, p. 5).

Com efeito, é com os depoimentos de alfabetizadores e alfabetizandos que o ritual fecha o seu ciclo da emoção, do verdadeiro, dos laços que unem todos que estão naquele momento na cerimônia. Diz um dos alfabetizadores: 


\section{pro.posições}

$e$-ISSN 1980-6248

http://dx.doi.org/10.1590/1980-6248-2016-0080

A minha experiência foi um desafio, trabalhei em uma sala na Fazenda Bititinga, zona rural, o acesso era difícil para os alunos e eles chegavam muito cansados após o trabalho. Para eles não desistirem dos estudos, eu tinha que dar aulas dinâmicas e que envolvessem a participação de todos. Todo dia um aluno era responsável por trazer uma informação diferente e apresentar para a sala. Eles também faziam paródias sobre seu trabalho, sua família, sua comunidade. Eles adoravam ir à escola. (AlfaSol, 2006, p. 6)

Mas é preciso ainda ao professor a cena dos agradecimentos: "Devo o meu crescimento profissional à AlfaSol. Foi depois de meu trabalho na organização que descobri minha verdadeira vocação, me dediquei à sala de aula e, com isso, veio o reconhecimento do meu trabalho" (AlfaSol, 2006, p. 5).

O depoimento de uma aluna, Gesina Oliveira, também está no registro da cerimônia e nele há a narrativa de si, tal como comporta um ritual de passagem:

Eu tinha muitas dificuldades quando não sabia ler e escrever, não gostava de sair de casa, tinha medo, eu não sabia pegar nenhum meio de transporte e me sentia incapaz. ...Eu gosto muito de ler a Bíblia e me interesso muito por livros de história e português, minhas matérias preferidas. (AlfaSol, 2006, pp. 6-8)

Ao analisarmos esses pronunciamentos de alfabetizandos e professora, associamo-nos ao modo como Foucault (2013, p. 59), em uma de suas aulas em 12 de janeiro de 1983, trata o tema do enunciado performativo: "vocês sabem bem que, para haver um enunciado performativo, é preciso que haja um contexto estritamente institucionalizado, um indivíduo que tenha o estatuto requerido ou que se encontre numa situação bem definida".

Embora sejam evidentes as regras presentes em uma cerimônia institucional clássica, destacamos na cerimônia descrita a interpenetração do universo da escolarização e com o mundo empresarial, pela presença de representantes de empresas, e também com o universo midiático, dada a participação de artistas das mídias de massa.

\section{Cerimônia do programa estadual da Bahia Todos Pela Alfabetização, realizada em Salvador em 2010}

No período entre 2003 e 2010, o discurso da política educacional enfatizou uma visão de educação republicana. Nesse sentido, autonomia, inclusão e diversidade passaram a ser elementos identificados com uma sociedade justa do ponto de vista da superação das 


\section{pro.posıções}

$e$-ISSN 1980-6248

http://dx.doi.org/10.1590/1980-6248-2016-0080

desigualdades sociais. O texto "Plano de Desenvolvimento da Educação de 2007" retrata bem esses enunciados. Em nível nacional, a alfabetização é orientada pelo Programa Brasil Alfabetizado desde 2003 (MEC). O programa, voltado para a alfabetização de jovens, adultos e idosos, é uma porta de acesso à cidadania e o despertar do interesse pela elevação da escolaridade, diz o MEC (portaldomec.gov.br).

O Governo do estado da Bahia criou em 2007, dentro do programa Brasil Alfabetizado, do Governo Federal, o Todos pela Alfabetização - Topa, programa que atende a jovens acima de 15 anos, adultos e idosos, com a perspectiva de que a alfabetização é um direito que não prescreve com a idade. Segundo a Secretaria do Estado da Bahia, esse programa chegou prioritariamente a populações indígenas e quilombolas, população carcerária, ciganos e pessoas com deficiência. Nesse estado, o programa, à época da cerimônia em análise, já havia atendido 751 mil pessoas alfabetizadas, estava com 185 mil pessoas em sala de aula, tinha 407 municípios atendidos e 675 entidades dos movimentos sociais e sindicais participantes.

O Topa realizou uma cerimônia de encerramento no dia 10 de dezembro de 2010, na Assembleia Legislativa, no Centro Administrativo da Bahia (CAB), na cidade de Salvador. Estiveram presentes mil alunos, representando todos os territórios de identidade do estado e os demais concluintes, além de educadores e, como convidados de honra, o Presidente da República, Luiz Inácio Lula da Silva; o Ministro da Educação, Fernando Hadad; o Governador, Jaques Wagner; e Dona Canô (mãe de Caetano Veloso e Maria Bethânia), tal como está no registro analisado (Bahia, 2010).

Nenhuma ação performativa do ritual é igual a outra, afinal o que a define é o contexto e, por isso, como defende Peirano (2003), a ação ritualística não pode ser definida de forma rígida. Assim sendo, dizemos que o ritual dessa cerimônia, em sua singularidade, tem semelhanças com as outras já indicadas neste artigo, a exemplo da cena solene desde o local onde ocorre a cerimônia, os convidados e a sequência ordenada das palavras, dos gestos e da simbologia. A cerimônia teve início com a execução do Hino Nacional, com a participação dos cantores Mariene de Castro, Adelmário Coelho, Bule-Bule, Andrea Daltro e Mateus Aleluia. Em seguida, a orquestra tocou o Hino ao Dois de Julho, interpretado pelo cantor Tatau.

A música é uma das experiências comunicativas na cosmologia do ritual. Os hinos em cenas ritualísticas associam palavras, gestos e pensamentos, atuando como comunicação de 


\section{pro.posıções}

$e$-ISSN 1980-6248

http://dx.doi.org/10.1590/1980-6248-2016-0080

sentimentos, valores, ética e estética na palavra, no som e no gesto, no complexo que é o ritual (Tambiah, 1995, p. 43).

A oradora da turma, Heloísa Santos da Silva, diante das autoridades, fez a leitura de um breve discurso de agradecimento ao Governador e ao Presidente. Em seu discurso, disse: “o Topa foi uma bênção e uma oportunidade que tive, aos 59 anos, de superar o analfabetismo. Tenho muita vontade de aprender e quero continuar a estudar" (Bahia, 2010).

Fábio Novaes Santos, 27 anos, surdo-mudo, segundo sua mãe Creuza Santos,

graças ao Topa, hoje, é outra pessoa ... a comunicação dele mudou depois que aprendeu a escrever nas aulas do programa. Foi muito importante porque, antes, ele estava sem estudar, sem estímulo. E agora ele aparenta estar mais animado e não quer mais parar.(Bahia, 2010)

O Presidente da República elogiou as histórias de dois alfabetizandos que, desde então, podem ler a Bíblia, ler jornal e sabem escrever a palavra "amar". Disse o Presidente, conforme registro no site oficial da Secretaria de Educação do Estado da Bahia: "Quero dizer que possivelmente não tenhamos, em lugar nenhum do Brasil, um programa de sucesso como este aqui da Bahia. Parabéns a todos os envolvidos no Topa, pois podem se tornar referência nacional na alfabetização de adultos" (Bahia, 2010, p. 1).

O Ministro da Educação, Fernando Haddad, afirmou que o Topa significa "um exemplo que a Bahia dá ao Brasil de resgate de uma dívida histórica com os baianos. No que diz respeito à alfabetização de adultos, a Bahia abraçou o projeto como nenhum outro estado" (Bahia, 2010, p. 1). Já o Governador enfatizou que: "Essa caminhada vai continuar e espero que, assim como outras doenças, o analfabetismo seja erradicado da Bahia como sonhou Cosme de Farias" (p. 1). Na cerimônia, houve, em seguida, a premiação de experiências inovadoras na prática alfabetizadora.

Há assim a ação de deferência (Goffman, 2011), a explicitação dos valores da ação alfabetizadora e os enunciados conotativos que tranquilizam a todos: babemus leitores. A cerimônia pode terminar. A cerimônia, ao sacralizar a alfabetização, atua como prática performática. Um dos aspectos mais importantes do ritual é a sua eficácia, como nos ensina Tambiah (1995, p. 44). Essa eficácia remete ao que defendeu Austin (1990): dizer alguma coisa é fazê-la. Os participantes constroem sentidos a partir dos valores que estão implicados na cosmologia e também passam pela experiência com diferentes meios de comunicação. 


\section{pro.posıções \\ $e$-ISSN 1980-6248}

http://dx.doi.org/10.1590/1980-6248-2016-0080

Recorro ao princípe Di Lampedusa (1963) para com ele afirmar: "Se queremos que tudo fique como está é preciso que tudo mude" (p. 32).

\section{Para concluir}

O devir do homem é a história do esgotamento de suas possibilidades. Susan Sontag (2015b)

As cerimônias neste texto, trabalhadas em sua estrutura, ordem e enunciados conotativos, explicitam valores, traduzem gestos de deferência, posicionam indivíduos. Estamos falando de indivíduos que, em seu processo educativo de escolarização, acolhem e se enredam em um jogo de linguagem no qual passam a afirmar-se como pessoas que não sabem de nada, que querem aprender qualquer coisa, expressando uma imensa gratidão pelo saber conquistado, e, principalmente, por poder agora ser cidadãos. Repetem em sua função, desde os primeiros programas de alfabetização, o enunciado: quando não sabia ler, era como se eu fosse cego. Essas narrativas em cerimônias de abertura ou encerramento de programas de alfabetização não seriam elas próprias, também, um modo de narrar contra si próprio?

Afirmamos ao longo deste texto que práticas ritualísticas como as cerimônias nos dão a certeza sobre o verdadeiro, elas nos autorizam a um determinado comportamento, gesto, discurso. Elas nos conduzem à ordem do discurso e, ao mesmo tempo, nos inserem em grupos sociais da sociedade, mesmo que essa inserção se dê de forma diferenciada.

Defendemos que a cerimônia tem a função social de dizer e produzir um discurso sobre a cultura, e tal prática traz para a cena a narrativa do adulto, sua reflexão sobre sua experiência de alfabetizando no contexto de uma relação com outras narrativas com mais poder discursivo, pois estão sustentadas no discurso do conhecimento científico. Nesse momento do ritual, há a qualificação, a classificação e a premiação daquele(a) que sabe ler, comportar-se em público, e, ao mesmo tempo, a desqualificação de quem não apresentar o que está na ordem do discurso.

$\mathrm{Na}$ cerimônia, o sujeito da educação - o adulto alfabetizado - faz o seu discurso em uma cena enunciativa na qual a institucionalidade lhe dá o direito da palavra; aliás, algum aluno precisa falar para que a cerimônia possa acontecer. Essa fala requer que se saiba qual o discurso 


\section{pro.posıções}

$e$-ISSN 1980-6248

http://dx.doi.org/10.1590/1980-6248-2016-0080

está autorizado pela própria institucionalidade da cerimônia, que se dá por meio da presença das autoridades mais do que pelo local, já que este pode ser, inclusive, qualquer espaço que, pela ação ritualística, se torna um ambiente institucional. A cerimônia ritualística promove também os cortes, os limites das palavras, os gestos, os comportamentos, de modo a sujeitar o indivíduo a regras que validam a sociedade letrada. A um só tempo, eleva e constrange. Subjetiva pelo saber ler e por tudo que sabia, mas que não tem valor social.

Com Foucault, fomos incitados a pensar sobre as técnicas de ritualização, classificação e normalização, por meio das quais os sujeitos da educação são situados no seu lugar hierárquico. $\mathrm{Na}$ perspectiva foucaultiana, o enunciado performativo consuma a coisa enunciada - para existir tal enunciado, precisa-se de um contexto no qual os elementos dados na situação sejam tais, que, pronunciados, segue-se um efeito, conhecido de antemão, codificado. Todavia, ao enunciado performativo, Foucault (2013) contrapõe o enunciado parresiático, "quando há liberdade na enunciação da verdade" [no cerne da qual] "não encontramos o estatuto social do sujeito, encontramos sua coragem" (p. 60).

Para Tambiah (1995), embora o ritual apresente as características da formalidade, da estereotipia, da redundância, a sua dimensão é também social e política. Assim, há que se pensar no imponderável. O seu conceito de cosmologia permite compreender que cerimônias e outros rituais oferecem contextos singulares nos quais podem dizer e fazer coisas diferentes.

Um convite à análise dos rituais também como pontos de fuga não só de enunciados ou à sua profanação como um contradispositivo.

\section{Referências}

Abbagnano, N. (2007). Dicionário de Flosofia (5a ed.) São Paulo: Martins Fontes.

Agamben, G. (2009). O que é um dispositivo? In G. Agamben, O que é o contemporâneo e outros ensaios (V. N. Honesko, Trad.). Chapecó: Argos.

AlfaSol (Alfabetização solidária). (2006, julho/dezembro). Escrevendo juntos, 34. Recuperado em setembro de 2015, de <http://docplayer.com.br/10224282-Escrevendo-umapublicacao-da-alfabetizacao-solidaria-julho-dezembro-no-34-escrevendo-juntos.html>. 


\section{pro.posições}

$e$-ISSN 1980-6248

http://dx.doi.org/10.1590/1980-6248-2016-0080

Alves, A. (2013, julho/dezembro). Sessão de encerramento do curso de alfabetização, realizada em Angicos no dia 2 de abril de 1963. In M. Guerra, \& C. Cunha, Sobre as 40 horas de Angicos, 50 anos depois (Discurso do Governador). Em Aberto, 26(90), 163-164.

Austin, J. L. (1990). Quando dizere é fazer: as palauras e ação. (D. M. de Souza Filho, Trad.). Porto Alegre: Artes Médicas.

Bahia. (2010). Secretaria de Educação do Estado. Programa Todos pela Alfabetiz̧ação (Topa). Recuperado em setembro de 2014, de <http://www.sec.ba.gov.br/topa/noticias>.

Barthes, R. (1988). Aula inaugural da cadeira de Semiologia Literária do Collège de France, pronunciada no dia 7 de janeiro de 1977 (L. Perrone-Moisés, Trad.) São Paulo: Cultrix.

Bourdieu, P. (1994). Lições da aula (Aula inaugural proferida no Collège de France, 2a ed., R. E. de Oliveira, Trad.). São Paulo: Ática.

Bourdieu, P. (2004). Coisas ditas (C. R. da Silveira, \& D. M. Pergorim, Trads.) São Paulo: Brasiliense.

Brayner, F. H. A. (2014, abril/junho). O clichê: notas para uma derrota do pensamento. Por uma consciência ingênua. Educação \& Realidade, 39 (2), 557-572.

Butler, J. (2003). Tráfico sexual: entrevista. Gayle Rubin com Judith Butler. Cadernos Pagu, 21, 157-209.

Carvalho, R. T. (2012). A qualidade social da Educação Básica no discurso do Ministério da Educação. Estudos de Sociologia, 2, 1, 1-10.

Castro, E. (2009) Vocabulário Foucault. Um percurso pelos seus temas, conceitos e autores. Tradução Ingrid Müller Xavier. Belo Horizonte: Autêntica, 2009.

Cavalcante, J. S. de L. (2016). O projeto social de escolarização das populações adultas: um problema biopolítico. In Anais on line do Colóquio Latino Americano de Biopolítica; Colóquio Internacional de Biopolitica e Educação; Seminário Internacional IHU. São Leopoldo. RS: Casa Leiria.

Durkheim, E. (1984). Sociologia. In J. A. (Org.), Durkheim (vol. 1, Coleção Grandes Cientistas Sociais). São Paulo: Ática. 


\section{pro.posıções}

$e$-ISSN 1980-6248

http://dx.doi.org/10.1590/1980-6248-2016-0080

Ferreira, A. (2013, julho/dezembro). Sessão de encerramento do curso de alfabetização, realizada em Angicos no dia 2 de abril de 1963 (Discurso do aluno já alfabetizado). In M. Guerra, \& C. Cunha, Sobre as 40 horas de Angicos, 50 anos depois. Em Aberto, 26 (90), 168.

Foucault, M. (1995). Sobre a genealogia da ética: uma revisão do trabalho. In H. Dreyfus, \& P. Rabinow (Org.), Foucault uma trajetória filosófica: para além do Estruturalismo e da Hermenêutica (pp. 253-278, V. P. Carrero, Trad.). Rio de Janeiro: Forense Universitária.

Foucault, M. (1999). A ordem do discurso (L. F. de A. Sampaio, Trad.). São Paulo: Loyola.

Foucault, M. (2001). Outros espaços. In M. B. da Motta (Org.), Michel Foucault: estética: literatura epintura, música e cinema (pp. 411-422, I. A. D. Barbosa, Trad.). Rio de Janeiro e São Paulo: Forense Universitária.

Foucault, M. (2013). O Governo de si e dos outros. Curso no Collège de France (1982-1983) (E. Brandão, Trad.). São Paulo: WMF Martins Fontes.

Freire, P. (1963-2014) Dois de abril de 1963, uma data para lembrar. In M. Gadotti (Org.), Alfabetizar e conscientizar: Paulo Freire, 50 anos de Angicos. 1a ed. São Paulo, SP: Instituto Paulo Freire.

Freire, A. M. A. (2006). Paulo Freire: uma história de vida. Indaiatuba, SP: Vila das Letras.

Goffman, E. (2011). Ritual de interação: ensaios sobre o comportamento face a face (F. R. R. da Silva, Trad.). Petrópolis: Vozes.

Gorki, M. (1976). Pequenos burgueses. (G. de Freitas, Trad.) São Paulo: Victor Civita.

Goulart, J. B. M. (2013, julho/dezembro). Sessão de encerramento do curso de alfabetização, realizada em Angicos no dia 2 de abril de 1963. In M. Guerra, \& C. Cunha, Sobre as 40 horas de Angicos, 50 anos depois (Discurso do Presidente). Em Aberto, 26(90), 165-167.

Hall, S. (1999). A identidade cultural na pós-modernidade (T. T. Silva, Trad.). Rio de Janeiro: DP\&A. Lampedusa, T. di. (1963). O leopardo (3a ed., R. Cabeçadas, Trad.) São Paulo: Difusão Europeia do Livro.

Leonine, L. (1995). Prefazione all'edizione italiana. In S. Tambiah, Rituali e cultura. (D. Garavini, Trad.). Bologna: Ediciones Italiana.

Lévi-Strauss, C. (1989). O pensamento selvagem (T. Pellegrini, Trad.). Campinas, SP: Papirus. 


\section{pro.posıções}

$e$-ISSN 1980-6248

http://dx.doi.org/10.1590/1980-6248-2016-0080

Lyotard, J.-F. (1988). A condição pós-moderna. Rio de Janeiro: José Olympio.

Ministério de Educação e Cultura. Programa Brasil Alfabetizado. Recuperado em (04/04/2015), de http://portal.mec.gov.br/programa-brasil-alfabetizado.

Ortiz, R. (2012). As formas elementares da vida religiosa e as Ciências Sociais Contemporâneas. Lua Nova, 87, 13-31.

Peirano, M. (2002). A análise antropológica de rituais. InM. Peirano (Org.), O dito e o feito: ensaios de antropologia dos rituais. Rio de Janeiro: Relume Dumará, Núcleo de Antropologia da Política/UFRJ.

Peirano, M. (2003). Rituais, ontem e hoje. Rio de Janeiro: Jorge Zahar.

Peirano, M. (2006). Temas ou teorias? O estatuto das noções de ritual e de performance. Campos, 7(2), 9-16. Recuperado em setembro de 2016, de <http://revistas.ufpr.br/campos/article/download/7321/5248>.

Rivière, C. (1996). Os ritos profanos (G. J. F. Teixeira, Trad.). Petrópolis, RJ: Vozes.

Sessão de encerramento do curso de alfabetização, realizada em Angicos no dia 2 de abril de 1963. (2013, jul. /dez.). In M. Guerra, \& C. Cunha, Sobre as 40 horas de Angicos, 50 anos depois. Em Aberto, 26 (90), 168.

Silva, T. T. (2000). Teoria cultural e educação: um vocabulário crítico. Belo Horizonte: Autêntica.

Silva, T. T. (2000). Teoria cultural e educação: um vocabulário crítico. Belo Horizonte: Autêntica.

Sloterdijk, P. (2000). Regras para o parque humano: uma resposta à carta de Heidegger sobre o humanismo (J. O. de A. Marques, Trad.). São Paulo: Estação Liberdade.

Sontag, S. (1987). Contra a interpretação (A. M. Capovilla, Trad.). Porto Alegre: L\&PM.

Sontag, S. (2015a). Entrevista completa para Revista Rolling Stone (R. Bettoni, Trad.). Belo Horizonte, Minas Gerais: Autêntica.

Sontag, S. (2015b). A vontade radical: estilos (J.R. Martins Filho, Trad.). São Paulo: Companhia das Letras.

Tambiah, S. J. (1995). Rituali e cultura (D. Garavini, Trad.). Bologna: Il Mulino. 


\section{pro.posıções \\ $e$-ISSN 1980-6248}

Tambiah, S. J. (1997). Continuidade, integração e horizontes em expansão. Entrevista concedida a Mariza Peirano, em 29 de novembro de 1996, na Universidade de Harvard, K. M. P. de Almeida, Trad.). MANA, 3(2), 199-219, 1997.

Turner, V. W. (2013). O processo ritual: estrutura e a antiestrutura (N. C. de Castro, \& R. A. Rosenbusch, Trads.). Petrópolis, RJ: Vozes.

Weber, S. (1984). Política e educação: o movimento de cultura popular no Recife. Revista de Ciências Sociais, 27, 233-262.

Woodward, K. (2000). Identidade e diferença: uma introdução teórica e conceitual. In T. T. Silva, S. Hall, \& K. Woodward, identidade e diferença: a perspectiva dos Estudos Culturais (T. T. Silva, Trad.). Petrópolis, RJ: Vozes.

Submetido à avaliação em 15 de junho de 2016; revisado em 13 de dez̧embro de 2016; aceito para publicação em 09 de maio de 2017. 